\title{
Amphotericin B-Deoxycholate is as Effective and Safe as the Costly Amphotericin B Colloidal Dispersion in the Treatment of Paediatric Invasive Fungal Infections
}

\author{
Sarinah Tamring ${ }^{1}$, Tey le Lane ${ }^{1}$, Hani Syazwani Mohd Shah ${ }^{1}$, \\ Harikrishnan Shanmuganathan ${ }^{1}$, Tzar Mohd Nizam Khaithir ${ }^{2}$, \\ Ahmad Nazrun Shuid ${ }^{3}$, Boekhtiar Borhanuddin ${ }^{3}$ and Isa Naina Mohamed ${ }^{3, *}$ \\ ${ }^{1}$ Faculty of Medicine, Universiti Kebangsaan Malaysia Medical Centre, Kuala Lumpur, Malaysia \\ ${ }^{2}$ Department of Medical Microbiology and Immunology, Universiti Kebangsaan Malaysia Medical Centre, \\ Kuala Lumpur, Malaysia \\ ${ }^{3}$ Pharmacoepidemiology and Drug Safety Unit, Department of Pharmacology, Faculty of Medicine, Universiti \\ Kebangsaan Malaysia, Kuala Lumpur, Malaysia
}

\begin{abstract}
Amphotericin B deoxycholate (AmBD) and amphotericin B colloidal dispersion (AmBCD) are the two most commonly used antifungals for invasive fungal infections (IFI) among paediatric patients. The objective of this pilot study was to compare the efficacy, adverse effects and cost-effectiveness between AmBD and AmBCD in the treatment of IFI among paediatric patients admitted at Universiti Kebangsaan Malaysia Medical Centre (UKMMC).

Methods: Secondary data analysis of the medical records of all paediatric patients with IFI was obtained and data extraction was performed for patients admitted between July 1, 2006 and June 30, 2011. Efficacy of treatment was determined and reports of adverse effects were noted.

Results: Between July 1, 2006 and June 30, 2011, thirty-five patients received AmBD-only treatment and five patients received AmBCD-only treatment. Twenty-four patients were males and the mean age was 7.18 (SD 4.59) years. On average, the AmBCD treatment course was significantly more expensive than AmBD $(p<0.01)$. Patients on AmBD had more adverse effects compared to those on AmBCD. However, there was no significant difference in severe adverse events between these groups. There was no significant difference in efficacy between these groups, in terms of IFI resolution or treatment duration.

Conclusion: These findings imply that the use of AmBD instead of AmBCD in IFI treatment among paediatric patients is justified, given its cost-effectiveness, as there was no significant difference in the efficacy or in the incidence of severe adverse effects between these two treatments.
\end{abstract}

Keywords: Amphotericin B, Amphotericin B colloidal dispersion, Amphotericin B deoxycholate, Liposomal Amphotericin B, Paediatrics Invasive Fungal Infections (IFI), Antifungals.

\section{INTRODUCTION}

Invasive fungal infections (IFI) remain one of the major causes of morbidity and mortality in the immunocompromised host [1]. IFI is associated with high mortality and health care cost worldwide [2]. A higher morbidity and mortality rate is seen in children [3-6]. Diagnosis is difficult and often based on the exclusion of bacterial and viral infections. Persistent fever in patients with neutropenia who are receiving broad-spectrum antibiotics may be the only clinical indication of an IFI. Only a small proportion of patients treated with antifungal agents have documented fungal infection. Therefore, an antifungal agent is often started when a clinically suggestive sign of IFI is present [7]. Under these circumstances, a broad-spectrum

*Address correspondence to this author at the Pharmacology Department, Faculty of Medicine, Universiti Kebangsaan Malaysia Medical Centre, Jalan Yaacob Latif, 56000 Cheras, Kuala Lumpur, Malaysia; Tel: +60391459545;

Fax: +60391459547; E-mail: isa@medic.ukm.my antifungal agent is used for empirical treatment. To date, intravenous amphotericin B has been the only available broad-spectrum antifungal agent. However, the use of amphotericin B is associated with infusionrelated toxicities, hepatotoxicity and nephrotoxicity, which limit its use [8].

Lipid formulations of amphotericin B were developed to enhance the therapeutic index of the parent compound while maintaining its antifungal activity. Three lipid formulations of amphotericin B are licensed and available [9]: (i) amphotericin B lipid complex (AmBLC), formed from amphotericin B complexed with dimyristoylphosphatidylcholine and dimyristoylphosphatidylglycerol; (ii) amphotericin B colloidal dispersion (AmBCD), composed of amphotericinB complexed with cholesterylsulphate; and (iii) liposomal amphotericin B (L-AmB), composed of amphotericin $B$ complexed with hydrogenated soy phosphatidylcholine, distearoyl, phosphatidylglycerol and cholesterol. All three lipid-based amphotericin B 
products differ in the type of phospholipid and the phospholipid:AmB ratio, which may be important determinants of fungicidal activity and toxicity [10]. At present, if a lipid-based amphotericin $B$ product is considered for use, L-AmB, AmBLC and AmBCD appear to be similar with respect to their efficacy against candidiasis and aspergillosis and the associated risk of nephrotoxicity. The latter two products cost significantly less than L-AmB [11].

AmBCD is a formulation of equal molar amounts of amphotericin B and sodium cholesteryl sulfate. Results of preclinical studies [12], uncontrolled [13-15], as well as retrospective, controlled clinical trials [16] of this agent have been promising. AmBCD is comparable in efficacy with amphotericin B-deoxycholate (AmBD), and renal dysfunction associated with $A m B C D$ was significantly less than with AmBD. However, infusionrelated events were more common with AmBCD treatment if compared to AmBD treatment [17].

AmBCD incurred significantly lower rates of nephrotoxicity than AmBD in a multicenter randomized, double-blind clinical trial of empirical antifungal therapy in febrile neutropenic patients $(20 \%$ and $52 \%$, respectively; $\mathrm{P}<0.001$ ), and the onset of renal toxicity was significantly delayed [17]. Another multicenter randomized, double-blind clinical trial that compared $A m B D$ with $A m B C D$ for treatment of invasive aspergillosis found that the rates of acute infusionrelated toxicity were higher in patients who received AmBCD than in those who received AmBD for both chills $(53 \%$ versus $30 \%)$ and fever ( $27 \%$ versus $16 \%$ ). The efficacy of these two antifungal agents, as judged by the rates of therapeutic response, appeared to be similar in both AmBCD and AmBD groups (52\% versus $51 \%$, respectively) [18].

The lipid-based amphotericin B is among the most expensive anti-infective agents, based on a defined daily dose. Their daily cost for an average adult ranges from around USD300 to USD1000, depending on the size of the institutional discounts on manufacturer's suggested retail price [19]. This is in contrast with the deoxycholate formulation that costs approximately USD5 per day in 2006. Prices of lipid-based amphotericin $B$ and deoxycholate formulation vary with the country of purchase and with time. However, the price gap difference of a higher price for lipid based formulation remains. With the exception of the licensing of L-AmB as the first-line therapy for febrile neutropenia in patients at high risk of IFI, the current US Food and Drug Administration (FDA) guidelines for these agents specify that they are to be used for patients who are intolerant of $\mathrm{AmBD}$ or whose conditions are refractory to it. In view of the cost data, the licensed indications have led many hospitals to adopt internal usage guidelines that mirror the FDA's licensing guidelines. Cost-effectiveness studies showed that this drug may not be as expensive as it appears when toxicity and efficacy are taken into consideration [9].

Currently there are few data describing the use of lipid formulation AmB in neonates and children [20]. Data for paediatric pharmacokinetic, safety and efficacy for the treatment options of IFI are sparse in paediatric patients compared with adults. Meanwhile, extrapolation using adult recommendations to paediatric practice should be made cautiously due to the presence of differences in epidemiological factors and the pharmacokinetics of antifungal agents between adult and paediatric patients [21].

The Sanford Guide to Antimicrobial Therapy is the current guideline adopted by Universiti Kebangsaan Malaysia Medical Center (UKMMC). The guideline recommends lipid formulation amphotericin B for empirical treatment of IFI. This is more important in IFI cases involving vulnerable patients such as children in which serious adverse events may cause long term morbidity. However, based on the current scenario in UKMMC, AmBD was still used in actual practice of IFI treatment due to financial constraints. Therefore, the issues of cost versus benefits and adverse effects need to be addressed in this situation. However, to date, there is no published study on this issue conducted in the Malaysian setting.

\section{METHODS}

This clinical observational study involved secondary data analysis [22] of paediatric patients' medical records in Universiti Kebangsaan Malaysia Medical Centre (UKMMC). The selected patients fulfilled the following inclusion criteria: (i) the patient had been prescribed with either intravenous AmBD or AmBCD; (ii) the patient's age was less than 18 years (according to the date of birth) when he/she first received the drug; (iii) the patient was admitted in UKMMC between July 1 2006 and June 302011.

Patients were excluded from the study based on the following exclusion criteria: (i) no amphotericin B was prescribed to the patient in the medical record; (ii) the type of amphotericin B cannot be determined from the medical record; (iii) the patient switched to another drug during the treatment course of IFI (except for the 
evaluation of adverse effects); (iv) the medical record had missing folder/data during the admission for IFI treatment; and $(v)$ the patient's file was not available in the Medical Record Unit. Patients who switched treatment were not included for evaluation of treatment efficacy in the study to avoid confounding factors in the analysis due to the switch. This study used a nonprobability purposive sampling method, whereby all subjects who fulfilled the selection criteria were included. Prior to the study initiation, ethics approval was obtained from UKMMC Ethics Committee (IRB Reference Number: UKM 1.5.3.5/244/FF-044-2012).

The research team had collaborated with the Pharmacy Department in UKMMC to obtain the medical record number (MRN) of the patients who had been prescribed with any types of intravenous amphotericin B. The medical record number of patients aged less than 18 years was identified and used to trace their medical record from the Medical Record Unit of Health Information Department. After the records were obtained, individual patients were screened to fulfil the rest of the study selection criteria. Data from the selected patients were then extracted from the record of their first episode of intravenous AmBD or intravenous AmBCD treatment course.

The data extraction was done using an internally validated data collection form. In this form, the IFI was classified into proven, probable and possible IFI according to the Revised Definition of Invasive Fungal Disease from the European Organization for Research and Treatment of Cancer/Invasive Fungal Infections Cooperative Group (EORTC) and the National Institute of Allergy and Infectious Diseases Mycoses Study Group (MSG) Consensus Group 2008 [19]. The efficacy of treatment with amphotericin B was determined based on the fulfilment of the following criteria: (i) the patient survived at the end of the treatment; and (iia) resolution of fever $\left(<38^{\circ} \mathrm{C}\right)$ and recovery of neutrophils $\left(\geq 0.5 \times 10^{9} / L\right)$ for 3 consecutive days, or (iib) documented clearance of blood from the specified fungal species, or (iic) documented resolution of radiological evidence of invasive fungal infection [23]. The duration of treatment course (in days) from the start of drug therapy until the achievement of the mentioned criteria was also extracted from the records. The adverse effects evaluated from the records were: severe adverse effects (nephrotoxicity and hepatotoxicity) and non-severe side effects [24] such as skin rash, fever, rigors, nausea and vomiting, hypokalemia, bronchospasm/cough, dyspnea and gastrointestinal tract upset. Nephrotoxicity was indicated by two-fold or greater elevation of serum creatinine above the baseline level [25], whereas hepatotoxicity was indicated by three-fold or greater elevation of serum alanine transaminase (ALT) or aspartate aminotransferase (AST) above the baseline levels [26]. The cost of treatment using the antifungals was calculated based on the number of vials of intravenous AmBD or intravenous AmBCD used (from the total accumulated dose throughout the treatment) times the drug cost per vials (as obtained from the Pharmacy Department).

For the purpose of research ethics, the computerised raw data from the data collection forms were anonymised. At the end of the study, all forms and data were stored securely at the Pharmacoepidemiology \& Drug Safety Unit. The collected data were then analysed using IBM SPSS Statistics (SPSS) version 16 software. Relevant descriptive analysis (frequency, means and standard deviations) was performed. Due to the small sample size and non-normality of the data in this study, nonparametric statistical analyses were performed. Comparisons between categorical data were analysed using Fisher's exact test, whereas comparisons between quantitative data were analysed using MannWhitney $U$ test. The accepted significance level of the statistical tests was set at alpha value of less than $5 \%$.

\section{RESULTS}

\section{Patients}

From the list obtained from Pharmacy Department, 72 patients less than 18 years old when they received intravenous Amphotericin B during the study period were identified. From these 72 patients, 32 patients were excluded from the study during the data collection period. Most of these patients (18) were excluded because they switched to another drug during the IFI treatment course (Table 1). Among the patients who switched treatments, 17 were initially started with AmBD, whereas one patient was initially started with AmBCD. Based on Table 2, the three main reasons for treatment switch among patient started with AmBD were the development of non-severe adverse effects $(29.4 \%)$, treatment failure $(23.5 \%)$, and development of severe adverse effects (17.6\%).

A total of 40 patients received AmBD-only or AmBCD-only treatment, without any switches to another drug during the study period. Among the 40 patients, 35 patients received $A m B D$ in their first treatment course, whereas 5 patients received AmBCD 
Table 1: Exclusion of Patients from the Study

\begin{tabular}{|l|c|}
\hline Reason of exclusion & No. of patients (\%) \\
\hline \hline Patient switched to another drug during the treatment course of IFI & $18(56.3)$ \\
\hline Patient's file was not available in the Medical Record Unit & $9(28.1)$ \\
\hline No amphotericin B prescribed to patients & $3(9.4)$ \\
\hline Patient's medical record has missing folder/data during admission for treatment of IFI & $1(3.1)$ \\
\hline Type of amphotericin B cannot be determined from the medical record & $1(3.1)$ \\
\hline Total & $32(100)$ \\
\hline
\end{tabular}

Table 2: Reasons of Switch to other Drugs throughout Treatment Course

\begin{tabular}{|l|c|c|}
\hline Reason of switch & \multicolumn{2}{|c|}{ No. of patients (\%) } \\
\cline { 2 - 3 } & $\begin{array}{c}\text { AmBD } \\
(\mathbf{n}=17)\end{array}$ & $5(29.4)$ \\
\hline \hline Development of other adverse effects & $4(23.5)$ & $0(0)$ \\
\hline Treatment with initial drug course was not efficacious (as evaluated by the attending doctor) & $3(17.6)$ & $0(0)$ \\
\hline Development of severe adverse effects & $1(5.9)$ & $0(0)$ \\
\hline Concurrent renal impairment & $1(5.9)$ & $0(0)$ \\
\hline Known better sensitivity to the switch drug & $1(5.9)$ \\
\hline Case of non-IFI & $2(11.8)$ & $1(100)$ \\
\hline Unknown reason (incomplete folder of medical record) & $0(0)$ \\
\hline
\end{tabular}

in their first treatment course. The demographic and clinical characteristics of the patients are presented in Table 3.

\section{Dosage}

The mean for the lowest dose of AmBD used was 0.48 (SD 0.10) $\mathrm{mg} / \mathrm{kg} / \mathrm{day}$, whereas the highest dose was 0.98 (SD 0.25) $\mathrm{mg} / \mathrm{kg} / \mathrm{day}$. The dose used in $A m B C D$ was higher, whereby the mean for the lowest dose was 0.84 (SD 0.29) $\mathrm{mg} / \mathrm{kg} /$ day and the highest dose was 1.78 (SD 0.18) mg/kg/day.

\section{Efficacy}

Among the 35 patients treated with AmBD, 32 treatments fulfilled the efficacy criteria, whereas three patients died during the treatment course. The treatment with AmBCD was efficacious for four patients, while only one patient died during the treatment course (Table 4). Odds ratio for the efficacious treatment outcome for AmBD compared to AmBCD was 2.67. However, analysis using Fisher's exact test showed no significant difference for the overall efficacious treatment outcome $(p>0.05)$. Comparison of efficacy was also done based on the analysis of the duration of treatment course. The average duration of treatment course for patients on AmBCD was longer compared to patient on AmBD (Table 4). However, non-parametric analysis using Mann-Whitney $U$ test showed no significant difference for the duration of treatment between AmBD and AmBCD ( $p>0.05)$.

\section{Adverse Effects}

For the analysis of adverse effects, all patients who received $A m B D$ or $A m B C D$ in their first treatment course, regardless of switching status, were included in the analysis. 51 patients received AmBD during their first treatment course, whereas seven patients received AmBCD during their first treatment course. AmBD and $A m B C D$ treatments were compared based on the occurrence of at least one adverse effect throughout the treatment course (Table 5). During AmBD treatment $(n=51), 40$ patients experienced at least one adverse effect, whereas nine patients did not experience any adverse effects. Two patients in the AmBD group were not included in the analysis due to missing data. Among the seven patients on AmBCD, only two patients experienced at least one adverse effect. Analysis using Fisher's exact test showed significant difference of the occurrence of adverse 
Table 3: Demographic and Clinical Characteristics of Patients Receiving either IV Amphotericin B Deoxycholate or IV Amphotericin B Colloidal Dispersion

\begin{tabular}{|c|c|c|c|}
\hline \multirow[t]{2}{*}{ Characteristics } & \multicolumn{3}{|c|}{ No. of patients (\%) } \\
\hline & $\begin{array}{l}\text { AmBD } \\
(n=35)\end{array}$ & $\begin{array}{c}\text { AmBCD } \\
(n=5)\end{array}$ & Total \\
\hline \multicolumn{4}{|l|}{ Age (years) } \\
\hline Mean (SD) & 7.05 (4.32) & $8.05(6.75)$ & $7.18(4.59)$ \\
\hline \multicolumn{4}{|l|}{ Gender } \\
\hline Male & $20(57.1)$ & $4(80.0)$ & $24(60.0)$ \\
\hline female & $15(42.9)$ & $1(20.0)$ & $16(40.0)$ \\
\hline \multicolumn{4}{|l|}{ Race } \\
\hline Malay & $21(60.0)$ & $3(60.0)$ & $24(60.0)$ \\
\hline Chinese & $9(25.7)$ & $1(20.0)$ & $10(25.0)$ \\
\hline Indian & $4(11.4)$ & 0 & $4(10.0)$ \\
\hline Others & $1(2.9)$ & $1(20.0)$ & $2(5.0)$ \\
\hline \multicolumn{4}{|l|}{ Primary diagnosis } \\
\hline Acute lymphocytic leukaemia & $15(42.9)$ & $2(40.0)$ & $17(42.5)$ \\
\hline Acute myeloid leukaemia & $11(31.4)$ & $0(0)$ & $11(27.5)$ \\
\hline Adrenocortical tumor & $1(2.9)$ & $0(0)$ & $1(2.5)$ \\
\hline Lymphoma & $0(0)$ & $1(20.0)$ & $1(2.5)$ \\
\hline Neuroblastoma & $3(8.6)$ & $0(0)$ & $3(7.5)$ \\
\hline Sarcoma & $1(2.9)$ & $0(0)$ & $1(2.5)$ \\
\hline Primary immunodeficiency & $2(5.7)$ & $0(0)$ & $2(5.0)$ \\
\hline Retinoblastoma & $1(2.9)$ & $0(0)$ & $1(2.5)$ \\
\hline Premature baby & $0(0)$ & $1(20.0)$ & $1(2.5)$ \\
\hline Others & $1(2.9)$ & $1(20.0)$ & $2(5.0)$ \\
\hline \multicolumn{4}{|l|}{ Types of invasive fungal infections (IFI) } \\
\hline Proven IFI & $3(8.6)$ & $4(80.0)$ & $7(17.5)$ \\
\hline Probable IFI & $1(2.9)$ & $1(20.0)$ & $2(5.0)$ \\
\hline Possible IFI & $31(88.6)$ & $0(0)$ & $31(77.5)$ \\
\hline
\end{tabular}

Table 4: Efficacy of Treatment Course

\begin{tabular}{|c|c|c|c|}
\hline Efficacy & $\begin{array}{l}A m B D \\
(n=35)\end{array}$ & $\begin{array}{c}\text { AmBCD } \\
(n=5)\end{array}$ & $\mathbf{p}$ \\
\hline \multicolumn{4}{|l|}{ Overall outcome of treatment [No. of patients (\%)] } \\
\hline Treatment was efficacious & $32(91.4)$ & $4(80.0)$ & $0.427^{\mathrm{a}}$ \\
\hline Patient died during the treatment course & $3(8.6)$ & $1(20.0)$ & \\
\hline \multicolumn{4}{|l|}{ Duration of treatment course (days) } \\
\hline Mean (SD) & $11.86(7.12)$ & $22.00(16.70)$ & $0.151^{b}$ \\
\hline
\end{tabular}

${ }^{a}$ Analysis was done using Fisher's exact test.

${ }^{\mathrm{b}}$ Analysis was done using Mann-Whitney U test.

effects between these antifungals $(p<0.05)$, where the odds ratio of adverse effect occurrence for AmBD compared to AmBCD treatment was 11.11.
Comparison was also made in terms of the total number of adverse effects between the two antifungals. On average, patients on $\mathrm{AmBD}$ experienced two 
Table 5: Adverse Effects throughout Treatment Course

\begin{tabular}{|c|c|c|c|}
\hline Adverse effects & $\begin{array}{l}\text { AmBD } \\
\left(n=51^{\star}\right)\end{array}$ & $\begin{array}{c}\text { AmBCD } \\
\left(n=7^{\star}\right)\end{array}$ & $\mathbf{p}$ \\
\hline \multicolumn{4}{|c|}{ Occurrence of adverse effects [No. of patients (\%)] } \\
\hline At least one adverse effect present & $40(81.6)$ & $2(28.6)$ & $\mathrm{p}=0.01^{\mathrm{a}}$ \\
\hline None & $9(18.4)$ & $5(71.4)$ & \\
\hline \multicolumn{4}{|l|}{ Total number of adverse effects } \\
\hline Mean (SD) & $1.65(1.42)$ & $0.86(1.46)$ & $\mathrm{p}=0.09^{\mathrm{b}}$ \\
\hline \multicolumn{4}{|c|}{ Occurrence of specific adverse effects [No. of patients (\% in treatment group)] } \\
\hline Hypokalemia & $20(40.0)$ & $1(14.3)$ & \\
\hline Fever & $15(30.6)$ & $2(28.6)$ & \\
\hline Rigors & $12(24.5)$ & $1(14.3)$ & \\
\hline Skin rash & $3(6.1)$ & $0(0.0)$ & \\
\hline Bronchospasm/cough & $3(6.1)$ & $0(0.0)$ & \\
\hline Vomiting & $3(6.1)$ & $0(0.0)$ & \\
\hline Nausea & $3(6.1)$ & $0(0.0)$ & \\
\hline Gastrointestinal side effects & $2(4.1)$ & $1(14.3)$ & \\
\hline Dyspnea & $1(2.0)$ & $0(0.0)$ & \\
\hline \multicolumn{4}{|l|}{ Occurrence of nephrotoxicity [No. of patients (\%)] } \\
\hline Yes & $4(8.0)$ & $0(0)$ & $\mathrm{p} \approx 1.00^{\mathrm{a}}$ \\
\hline No & $46(92.0)$ & $7(100)$ & \\
\hline \multicolumn{4}{|l|}{ Occurrence of hepatotoxicity [No. of patients (\%)] } \\
\hline Yes & $8(16.0)$ & $0(0)$ & $\mathrm{p}=0.58^{2}$ \\
\hline No & $42(84.0)$ & $7(100)$ & \\
\hline
\end{tabular}

${ }^{a}$ Analysis was done using Fisher's exact test.

${ }^{\mathrm{b}}$ Analysis was done using Mann-Whitney U test.

*Including patients who switched drug after the first treatment course, as well as those with partially missing data.

adverse effects compared to one adverse effect for patients on AmBCD. Further focus on the occurrence of specific adverse effects experienced by patients on AmBD treatment showed that the incidence of hypokalemia had the highest frequency $(40.0 \%)$, followed by fever (30.6\%) and rigors (24.5\%) (Table 5). However, this study found no significant difference between these drugs in terms of the occurrence of severe adverse effects, as determined by the presence of nephrotoxicity or hepatotoxicity during the treatment course (Table 5).

\section{Drug Cost}

AmBCD treatment was significantly $(p<0.01)$ more expensive compared to AmBD with the mean drug cost of RM4476 (SD RM3440) versus RM136 (SD RM188) (Table 6).

\section{DISCUSSION}

This study demonstrated no significant difference for the overall treatment outcome and duration of

Table 6: Drug Cost throughout Treatment Course

\begin{tabular}{|c|c|c|c|}
\hline Types of amphotericin B & N & $\begin{array}{c}\text { Mean (SD) } \\
\text { (RM) }\end{array}$ & p \\
\hline \hline AmBD & 35 & $136(188)$ & $0.002^{9}$ \\
\hline AmBCD & 5 & $4476(3440)$ & \\
\hline
\end{tabular}

${ }^{9}$ Analysis was done using Mann-Whitney $\mathrm{U}$ test. 
treatment between $A m B D$ and $A m B C D$. This finding was similar to two multicenter, randomized, doubleblind clinical trial studies done by White et al. (1998) and Bowden et al. (2002). The former study compared AmBD with AmBCD for the empirical treatment of febrile neutropenia involving adult and paediatric patients. The efficacy of treatment in that study was compared based on patient's survival and defervesence for 48 hours without premature discontinuation of the drug study. The study reported no significant difference in efficacy between the two drugs [17]. Bowden et al. (2002) compared AmBD and $A m B C D$ in cases of proven and probable invasive aspergillosis among adult and paediatric patients. The efficacy of AmBD and AmBCD was also reported to be similar [18].

Sandler et al. (2000) conducted a small prospective, double blind, randomized trial for the empirical treatment of febrile neutropenia, which focused on paediatric patients only. A total of 21 patients on AmBD were compared with 25 patients on AmBCD. Treatment efficacy was determined based on the survival of at least seven days post-study with resolution of fever and recovery of neutrophil level. The study also reported no significant difference of treatment efficacy between the antifungals [27].

Although the current study demonstrated that the odds of having at least one adverse effect was lower in AmBCD treatment compared to AmBD treatment, there was no difference between AmBD and AmBCD for the occurrence of nephrotoxicity and hepatotoxicity. These findings were in contradiction with several past studies [18-19]. White et al. (1998) demonstrated that more patients on AmBCD experienced infusion-related adverse effects [17]. Among their subjects, $99 \%$ of the patients who were on AmBCD reported one or more adverse effects compared to $92 \%$ of the patients who were on AmBD $(p=0.014)$ [17]. Meanwhile, the development of renal toxicity (with or without nephrotoxic chemotherapy agents) was significant in patients treated with AmBD and the duration before the development of renal toxicity was also shorter compared to AmBCD. Additionally, the study found significant increase of ALT among patients on AmBCD, but no significant change was observed in the levels of AST and other liver biochemistry profiles. Another study, by Bowden et al. (2002), also demonstrated that the occurrence of nephrotoxicity was higher in AmBD $(p=0.002)$, which has a faster time onset for the development of nephrotoxicity. However, acute infusion-related chills and fever incidence were significantly higher in AmBCD [13]. A review by Kleinberg (2006) also summarized that the reported incidence of nephrotoxicity (as defined by doubling of baseline creatinine levels) in lipid formulations AmB occurred at lower rates compared to AmBD [9]. The overall rate of nephrotoxicity in AmBCD was $13 \%$ compared to $53 \%$ in $A m B D$, based on a retrospective review of $A m B D$ treatment of fungal infections done in bone-marrow transplant recipients in five centres. The nephrotoxicity incidence of the other lipid formulations AmB was reported to be nearly similar to AmBCD (13\% in AmBLC and $12 \%$ in L-AmB). The contradictions between the results of these past studies [9, 18-19] and the current study may be contributed by the lower dose of AmBD prescribed $(0.48-0.98 \mathrm{mg} / \mathrm{kg} /$ day $)$ and the lower dose of AmBCD prescribed (0.84 - 1.78 $\mathrm{mg} / \mathrm{kg} / \mathrm{day}$ ) in the current study, if compared to the past studies. The doses used by White et al. (1998) were 4 $\mathrm{mg} / \mathrm{kg} / \mathrm{day}$ for $\mathrm{AmBCD}$ and $0.8 \mathrm{mg} / \mathrm{kg} /$ day for AmBD [18], whereas Bowden et al. (2002) prescribed 6 $\mathrm{mg} / \mathrm{kg} / \mathrm{day}$ for $A m B C D$ and $1.0-1.5 \mathrm{mg} / \mathrm{kg} / \mathrm{day}$ for $A m B D$ [19]. The use of a lower dose of AmBD, as observed in our study, may reduce the adverse effects that might have happened to those who were prescribed AmBD at a higher dose. Other possible factors in explaining the difference in findings include different demography of study population with current study. This study only focused on paediatric patients and compared the two antifungals during the first treatment course of the drugs. In comparison to both White et al. (1998) and Bowden et al. (2002) who included adults patients who may have had a longer history of primary underlying diagnosis and therefore lead to longer history of exposure to previous nephrotoxic drugs.

In terms of cost, the current study showed that AmBCD treatment was significantly more expensive than AmBD. This is consistent with a review by Robinson and Nahata (1999) that compared the costs of the conventional and the three lipid formulations of amphotericin B for one-month treatment in a $30 \mathrm{~kg}$ child and a $70 \mathrm{~kg}$ adult patient at recommended doses [28]. AmBD was shown to be the least expensive product, while Amphotericin B lipid complex (AmBLC) was the least expensive among the three lipid formulations. In another study, the estimated daily infection drug-treatment cost for a $70 \mathrm{~kg}$ adult patient who was given L-AmB at a dose of $5 \mathrm{mg} / \mathrm{kg}$ was USD1300, if compared to a daily dose of $1 \mathrm{mg} / \mathrm{kg}$ AmBD that would cost only USD24 (on the basis of the average wholesale price) [11]. 
This current study demonstrated that the majority of the paediatric patients in the sampling frame who required treatment of IFI with $A m B$ were patients with haematological malignancy. In Malaysia, the incidence of paediatric cancer is about 77.4 per million children aged less than 15 years, while data from the Malaysian National Cancer Registry Report 2007 showed that leukemia is the most frequent cancer in children (48.0\% in male and $44.5 \%$ in female) [29].

Based on the original approved FDA indication, $A m B C D$ is indicated for the treatment of invasive aspergillosis in patients who are refractory or intolerant to AmBD at therapeutic doses. However, the aforementioned review by Robinson and Nahata (1999) noted that one demonstrated advantage of lipid formulation $A m B$ is that larger doses can be given over longer periods, with relatively lower toxicity, than AmBD. Hence, they concluded that patients who potentially required high dose or prolonged therapy with $A m B D$ are especially at risk of developing nephrotoxicity and could potentially benefit from one of the lipid formulations of AmB [28]. Therefore, AmBCD should be considered in the management of IFI in patients with dose-limiting renal insufficiency, in patients who are intolerant of amphotericin $\mathrm{B}$, and in patients with specific fungal infections that are progressive despite treatment with AmBD.

This study justified the use of AmBD in IFI treatment among paediatric patients in the current local practice. The justification was made in view of the lack of significant difference in the efficacy and severe adverse effects between these two treatments, as well as the fact that AmBD treatment cost significantly less than AmBCD. In the local setting, expensive drug acquisition cost may hinder the wide usage of $A m B C D$ in the Malaysian general population.

Several limitations in this study need to be considered. First, the analysis of the treatment efficacy was done based on the general classification of IFI treated with $A m B$, without further classifying them based on severity. This was due to the small sample size available in the current study. Hence, the analysis of efficacy, in terms of the duration of treatment, may be confounded by the disease pathology, with the possibility of different time intervals required for resolution. Second, during the data collection period, the research team had extracted only the acute infusion-related adverse effects that were recorded as "being observed during the infusion of amphotericin B" to increase the certainty that the adverse effects were related to the amphotericin B infusion. Third, a detailed pharmacoeconomics analysis should include parameters such as intensive care cost needed for dialysis, relapse or treatment failure, diagnostic procedure costs, and the cost of premedications used to minimize infusion-related adverse effects. Fourth, this study was done in a single centre with a small sample size. Since the results of this study suggest that the more affordable AmBD treatment may be as effective as AmBCD treatment in children with IFI, wider studies should be undertaken on a larger study population.

\section{CONCLUSION}

The usage of AmBD for treatment of IFI in paediatric patients is justified with reduced cost and no significant difference in terms of efficacy and severe adverse effects compared with AmBCD.

\section{ACKNOWLEDGEMENT}

1. Head of department and staff of Medical Record Unit (Health Information Department), Universiti Kebangsaan Malaysia Medical Centre (UKMMC).

2. Professor Dr. Hamidah Alias, Department of Paediatrics, Universiti Kebangsaan Malaysia Medical Centre (UKMMC).

\section{COMPETING INTEREST STATEMENT}

All authors have no support from any organisation for the submitted work; no financial relationships with any organisations that might have an interest in the submitted work in the previous three years, no other relationships or activities that could appear to have influenced the submitted work.

\section{ABBREVIATIONS}

$$
\begin{aligned}
& \text { AmBLC }=\text { Amphotericin B lipid complex } \\
& \text { AmBCD }=\text { Amphotericin B colloidal dispersion } \\
& \text { AmBD }=\text { Amphotericin B-deoxycholate } \\
& \text { FDA } \quad=\text { Food and Drug Administration } \\
& \mathrm{IFI} \quad=\text { Invasive fungal infection } \\
& \mathrm{L}-\mathrm{AmB} \quad=\text { Liposomal amphotericin B } \\
& \mathrm{RM} \quad=\text { Ringgit Malaysia }
\end{aligned}
$$




\section{UKMMC = Universiti Kebangsaan Malaysia Medical Centre}

USD = United States Dollar

\section{REFERENCES}

[1] Pizzo PA, Robichaud KJ, Gill FA, Witebsky FG. Empiric antibiotic and antifungal therapy for cancer patients with prolonged fever and granulocytopenia. Am J Med 1982; 12: 101-111.

http://dx.doi.org/10.1016/0002-9343(82)90594-0

[2] Zaoutis TE, Argos J, Chu J, Berlin JA, Walsh TJ, Feudner C. The epidemiology and attributable outcomes of candidemia in adults and children hospitalized in the United States: a propensity analysis. Clin Infect Dis 2005; 41: 1232-1239. http://dx.doi.org/10.1086/496922

[3] Rodriguez-Nunez A. Incidence and mortality of proven invasive Candida infections in paediatric intensive care patients. Infection Control and Hospital Epidemiology 2011; 22: 477-478.

http://dx.doi.org/10.1086/503410

[4] Walmsley S, Devi S, King S, Schneider R, Richardson S, Ford-Jones L. Invasive Aspergillus infections in a paediatric hospital: a ten-year review. Pediatr Infect Dis J 1993; 12: 673-682.

http://dx.doi.org/10.1097/00006454-199308000-00009

[5] Abbasi S, Shenep JL, Hughes WT, Flynn PM. Aspergillosis in children with cancer: a 34-year experience. Clin Infect Dis 1999; 29: 1210-1219.

http://dx.doi.org/10.1086/313445

[6] Pappas PG, Rex JH, Lee J, et al. A prospective observational study of candidemia: epidemiology, therapy and influences on mortality in hospitalized adult and paediatric patients. Clin Infect Dis 2003; 37: 634-643. http://dx.doi.org/10.1086/376906

[7] EORTC International Antimicrobial Therapy Co-operative Group. Empiric antifungal therapy in febrile granulocytopenia. Am J Med 1989; 86: 668-672. http://dx.doi.org/10.1016/0002-9343(89)90441-5

[8] Goodwin SD, Cleary JD, Walawander CA, Taylor JW, Grasela TH. Pretreatment regimens for adverse events related to infusion of amphotericin B. Clin Invest Dermatol 1995; 20: 755-761.

[9] Kleinberg $M$. What is the current and future status of conventional amphotericin B? Int $\mathrm{J}$ of Antimicrob Agents 2006; 27S: S12-S16.

http://dx.doi.org/10.1016/j.ijantimicag.2006.03.013

[10] Joly V, Bolard J, Saint-Julien L, Carbon C, Yeni P. Influence of phospholipid/amphotericin B ratio and phospholipid type on in vitro renal cell toxicities and fungicidal activities of lipidassociated amphotericin B formulations. Antimicrob Agents Chemother 1992; 36: 262-266. http://dx.doi.org/10.1128/AAC.36.2.262

[11] Wong-Beringer A, Jacobs RA, Guglielmo BJ. Lipid formulations of Amphotericin B: Clinical Efficacy and Toxicities. Clin Infect Dis 1998; 27: 603-618.

http://dx.doi.org/10.1086/514704

[12] Allende MC, Lee JW, Francis $P$, Garrett K, Dollenberg $H$, Berenguer J, Lyman CA, Pizzo PA, Walsh TJ. Dose-dependent antifungal activity and nephrotoxicity of amphotericin B colloidal dispersion in experimental pulmonary aspergillosis. Antimicrob Agents Chemother 1994; 38: 518-22. http://dx.doi.org/10.1128/AAC.38.3.518

[13] Bowden RA, Cays M, Gooley T, Mamelok RD, Van Burik JA. Phase I study of amphotericin B colloidal dispersion for the treatment of invasive fungal infections after marrow transplant. J Infect Dis 1996; 173: 1208-15.

http://dx.doi.org/10.1093/infdis/173.5.1208
[14] Noskin GA, Pietrelli L, Coffey G, Gurwith M, Liang LJ. Amphotericin B colloidal dispersion for treatment of Candidemia in immunocompromised patients. Clin Infect Dis 1998; 26: 461-7.

http://dx.doi.org/10.1086/516314

[15] Herbrecht R, Letscher V, Andres E, Cavalier A. Safety and efficacy of amphotericin B colloidal dispersion. Chemotherapy 1999; 45(suppl 1): 67-76. http://dx.doi.org/10.1159/000048472

[16] White MH, Anaissie EJ, Kusne S, Wingard JR, Hiemenz JW, Cantor A, Gurwith M, Mond CD, Mamelok RD, Bowden RA. Amphotericin B colloidal dispersion vs. amphotericin B as therapy for invasive aspergillosis. Clin Infect Dis 1997; 24: 635-42.

[17] White $\mathrm{MH}$, Bowden RA, Sandler ES, et al. Randomized, double-blind clinical trial of amphotericin B colloidal dispersion vs. amphotericin B in the empirical treatment of fever and neutropenia. Clin Infect Dis 1998; 27: 296-302. http://dx.doi.org/10.1086/514672

[18] Bowden R, Chandrasekar P, White MH, Li X, Pietrelli L, Gurwith M, Burik JAV, Laverdiere M, Safrin S, Wingard JR. A double-blind, randomized, controlled trial of amphotericin B colloidal dispersion versus amphotericin B for treatment of invasive aspergillosis in immunocompromised patients. Clin Infect Dis 2002; 35: 359-366.

http://dx.doi.org/10.1086/341401

[19] De Pauw B, Walsh TJ, Donnelly JP, et al. Revised definitions of invasive fungal disease from the European organization for research and treatment of cancer/invasive fungal infections cooperative group and the national institute of allergy and infectious diseases mycoses study group (EORTC/MSG) consensus group. Clin Infect Dis 2008; 46: 1813-21. http://dx.doi.org/10.1086/588660

[20] Pappas PG. Clinical practice guidelines for the management of Candidiasis: 2009 update by the infectious diseases society of America. Clin Infect Dis 2009; 48: 503-35. http://dx.doi.org/10.1086/596757

[21] Katragkou A, Roilides E. Best practice in treating infants and children with proven, probable or suspected invasive fungal infections. Curr Opin Infect Dis 2011; 24: 225-229. http://dx.doi.org/10.1097/QCO.0b013e3283460e22

[22] Rohrig B, du Prel JB, Blettner M. Types of study in medical research. Dtsch Arztebl Int 2009; 106(15): 262-8.

[23] Segal $B H$, Herbrecht $R$, Stevens DA, et al. Defining responses to therapy and study outcomes in clinical trials of invasive fungal diseases: Mycoses study group and European organization for research and treatment of cancer consensus criteria. Clin Infect Dis 2008; 47: 674-83. http://dx.doi.org/10.1086/590566

[24] Laniado-Laborin R, Cabrales-Vargas MN. Amphotericin B: side effects and toxicity. Rev Iberoam Micol 2009; 26(4): 223227.

http://dx.doi.org/10.1016/j.riam.2009.06.003

[25] Bellomo R, Ronco C, Kellum JA, Mehta RL, Palevsky P Acute renal failure - definition, outcome measures, animal models, fluid therapy and information technology needs: the Second International Consensus Conference of the Acute Dialysis Quality Initiative (ADQI) Group. Crit Care 2004; 8: R204-R212. http://dx.doi.org/10.1186/cc2872

[26] U.S. Department of Health and Human Services Food and Drug Administration, Center for Drug Evaluation and Research (CDER) \& Center for Biologics Evaluation and Research (CBER) 2009. Guidance for Industry Drug-Induced Liver Injury: Premarketing Clinical Evaluation.

[27] Sandler ES, Mustafa MM, Tkaczewski I, et al. Use of Amphotericin B Colloidal Dispersion in Children. J Pediatr Hematol Oncol 2000; 22(3): 242-246. http://dx.doi.org/10.1097/00043426-200005000-00009 
[28] Robinson RF, Nahata MC. A comparative review of conventional \& lipid formulations of amphotericin B. J Clin Pharm Ther 1999; 24: 249-257. http://dx.doi.org/10.1046/j.1365-2710.1999.00220.x
[29] Ministry of Health Malaysia's National Cancer Registry Report. Malaysia Cancer Statistics - Data and Figure 2007.

Received on 21-07-2014

Accepted on 23-08-2014

Published on 11-11-2014

DOI: http://dx.doi.org/10.6000/1927-5951.2014.04.04.1

(C) 2014 Tamring et al.; Licensee Lifescience Global.

This is an open access article licensed under the terms of the Creative Commons Attribution Non-Commercial License (http://creativecommons.org/licenses/by-nc/3.0/) which permits unrestricted, non-commercial use, distribution and reproduction in any medium, provided the work is properly cited. 